\title{
Respecting Parent's Cultural Beliefs or Saving Child's Life: an Ethical Dilemma Surrounding Blood Transfusion
}

\author{
Shela Akbar Ali Hirani* \\ PhD Candidate, University of Alberta, Canada
}

Received: 制 January 12, 2018; Published: 制 January 24, 2018

*Corresponding author: Shela Akbar Ali Hirani, PhD Candidate, University of Alberta, Faculty of Nursing, Office \# 4-171 Edmonton Clinic Health Academy (ECHA), Faculty of Nursing, University of Alberta, 11405 - 87 Ave., Edmonton, Alberta, Canada

\section{Abstract}

Refusal to a medically justified treatment based on cultural beliefs is one of those challenging situations that raise several ethical, moral and legal issues in the health care settings, especially in pediatric settings. This paper presents a case scenario involving a minor who required a blood transfusion, however, the cultural beliefs of child's surrogate decision makers were against the recommended medical treatment. In view of the clinical scenario, this paper proposes positions that can be considered while encountering similar scenario and shares recommendations to improve the handling of ethical dilemmas in clinical settings.

Keywords: Pediatric setting; Ethical dilemma; Minor; Surrogate decision making; Best interest

\section{Introduction}

\section{Respecting Parent's Cultural Beliefs Or Saving Child's Life: An Ethical Dilemma Surrounding Blood Transfusion}

Healthcare professionals are morally obliged to restore patients' life while respecting patients' values and beliefs. Though abiding both the obligations apparently appears simple, healthcare professionals often face challenges to maintain a balance between these two obligations. Refusal to a medically justified treatment based on cultural beliefs is one of those challenging situations that raise several ethical, moral and legal issues in the health care setting. In fact, the challenge becomes double if the patient is minor, the situation is an emergency scenario, and the conflict is because of parents' cultural values. Parent's refusal to child's treatment considering cultural beliefs is one of the commonest satiations in pediatric setting [1]. While presenting a case scenario in a pediatric setting, this paper analyzes the encountered ethical dilemma, proposes positions that can be considered while encountering similar scenario, and shares recommendations to improve the handling of ethical dilemmas in clinical settings.

\section{Case Scenario}

A three years old child was brought to a tertiary care setting of Pakistan from a remote area of the country where health care facilities were not available. The child was in shock, unconscious and was suffering from severe anemia (Hemoglobin level $3 \mathrm{gm} /$ dl). Considering his serious condition, the child was admitted to pediatric special care unit of the tertiary care setting. Child's blood reports confirmed that he was having Thalassemia Major. To manage child's condition, blood transfusion was ordered by the physician. However, child's family refused the blood transfusion by stating that it is their cultural belief that child should not be receiving anybody else's blood, except his father's blood. The justification of family for refusing the donor's blood was that the donor might hold different caste, religion, and creed than theirs. Though prima facie the situation appears simple, it has lots of ethical issues.

Medically the safest option was transfusing the screened blood of the available donor to the child, however, the family refused to give consent. As per child's family, only father's blood should be given to the child and the treatment should be carried out in the light of their cultural beliefs. However, healthcare professionals were of the view that transfusion of father's unscreened blood could cause harm to that child if father's blood group does not match or it carries any infectious disease. Also, from health care perspective, another view was that sending father's blood for screening would take 8-10 hours; hence, delay in treatment might cause the death of a child. The ethical dilemma here was whether the primary health care team should respect value beliefs of child' surrogate decision 
makers or health team should override family's beliefs to save child's life. The ethical principles that were in conflict here were autonomy of child's parents versus non-maleficence of the child.

\section{Analysis of the Ethical Dilemma}

In the presented situation, one can realize the involvement of multiple people and the underlying challenges that they were facing. Firstly, the patient was involved as a minor client who needs urgent treatment to survive. The child was quite young to decide for own self and holds dependency over surrogate decision makers. In fact, child's survival with quality of life was only possible if the right decision is taken in child's best interest. Secondly, child's parents and family members were involved as child's surrogate decision makers who want to save child's life but need treatment in the light of their cultural beliefs. From family's perspective, the scenario was challenging because from the socio-cultural point of view they did not want to neglect their ancestors' values, and simultaneously they did not wish to lose their child. Thirdly, in that scenario, the healthcare professionals were involved who wanted to save child's life in the light of their professional obligations.

No doubt they are committed to providing culturally appropriate quality care to patients and their family members, they did not want to lose the child and face the guilt of not saving child's life by transfusing the screened blood. Analysis of scenario raises the question that what needs to be considered to take the decision for this minor client that is medically and culturally appropriate? Best interest standards' are considered as a practical approach to the clinical situation where healthcare professionals have to decide for the clients who are incompetent/minor and require immediate medical attention [2-4]. The best interest standards enable healthcare professionals to protect the well-being of clients by assessing the risk and benefits of all the available treatment options and their implications [5]. The literature further highlights the importance of gathering data, analyzing scenario from multiple dimensions, thoughtfully considering the subjective and objective evidence to reach a decision, and considering short term and longterm implications of the decision [6,7]. In view of the situations where surrogate decision making is involved, literature asserts that it is imperative that health team assess surrogate decision maker's capacity for decision making, their attitude towards patients, their level of commitment, and justification that they hold to refuse the treatment [8]. Hence, it is suggested that if surrogate's preference for treatment is revealing more harm than benefits then health care team should intervene appropriately.

\section{Proposed Positions for Ethical Decision Making}

In view of the case scenario and literature, three positions are proposed below while highlighting their benefits and consequences.

\section{First Position}

Father's blood should be sent for screening, and if the screening reports are satisfactory then the child should be transfused father's screened blood.
A. Benefits: Transfusion of father's screened and compatible blood will assure that health care professionals are preventing a child from potential harm of unscreened blood. By having a proper screening of father's blood, it would be assured that blood is safe and therapeutic [9]. This position would be in coherence with hospital policy and WHO guidelines that recommend rigorous screening of the donated blood to assure the safety of the blood recipients [10]. By taking this position, child's life can be saved if father's blood is declared compatible and safe. In fact, this position would satisfy child's family and would result in treatment continuation for the patient. This position will facilitate healthcare professionals to respect parents' autonomy and promote treatment compliance. As one of the drawbacks of this position is a delay in patient's treatment, non-blood treatment option can be considered to temporary manage child's condition [11]. This position may have a good outcome for the patient if father's blood meets medical requirements.

B. Consequences: While taking this position, one must consider the involved risks for the patient and for other people involved in the scenario. Firstly, benefit out of this treatment could not be achieved if after a delay of 8-10 hours father's blood is not reported as compatible or safe for the child. Secondly, this position would cause a delay of 8-10 hours in patients' treatment; therefore, one could anticipate more harm versus benefit for the child. In that situation, this position could have likely poor outcome versus good outcome for the child. In actual scenario, this position was taken to save the child's life, however, the child ended up with the poor outcome due to delay in treatment. Also, non-blood treatment did not prove to be effective for this child. Contrary to above, if father blood group is found compatible and declared as suitable then definitely child's life would be saved but still, this stand would not be in best interest of father because physiologically father of a Thalassemia Major patient would be suffering from Thalassemia minor and associated anemia, hence it might not be in best interest of the father to donate blood to his child on weekly basis. While considering this position it is essential for the healthcare professionals to think that should they recommend the father to put his life at risk for the sake of child's treatment and is it right to put child's best interest at the top or father's best interest? So here, the ethical principles of conflict are beneficence of child versus non-maleficence of the father.

\section{Second Position}

For managing this emergency situation, hospital management should take a legal stand and ensure treatment continuity by transfusing donor's blood (someone else's screened blood).

A. Benefits: This position would be the safest option for the child. Though this position would override parent's autonomy, the child would receive screened blood at the right time. This would be the safest option for the likely good outcome. Hence, this position could best fulfill short term goals for the patient's management and can protect the child from potential medical neglect. Although this position goes against parents' decision, can save child's life in an 
emergency situation. Literature supports that ethically and legally parents' decision could be disqualified if they are not in child's best interest $[1-4,12,13]$. The literature further reveals that some countries have legislation that permits health team to transfuse blood to a child despite their parents do not give the consent $[14,15]$. Above all, this position would not only ensure the best interest of the child but also minimize health risk for child's father having Thalassemia minor.

B. Consequences: No doubt, this position would assure nonmaleficence for a child but would show disrespect towards value beliefs and autonomy of child's surrogate decision makers. Also, this position would reveal coercion and paternalistic approach of the healthcare team members. In view of literature, some of the serious repercussions of these actions include feelings of powerlessness and loss of control among surrogate decision makers [16] and affected trusting relationships between them and healthcare professionals [1]. As Thalassemia Major is a lifelong condition that requires lifelong management with blood transfusion, this position may adversely affect child's future treatment plans. Also, taking this stand holds the possibility that the child might regret later in life for receiving someone else's blood rather than his father's blood in view of their cultural values and beliefs. This confirms that this position offers short term solution but holds long term repercussions.

\section{Final Position}

As child's advocate, health team should negotiate with child's family and empower them to select safest treatment option for the child

A. Benefits: This position will assist patients' parents in the decision-making process and empower child's parents. While taking this position, healthcare professional can empower child's family by providing information about patient's scenario, explaining the emergent nature of the situation, sharing an opinion from health team perspectives, and enabling them to realize a riskbenefit analysis of each of the identified options, and assisting them to select treatment option in the best interest of child and his father. Counseling fosters the trusting relationship between healthcare professionals and surrogate decision makers [16] and facilitates in exploring possible reasons for treatment refusal [17]. Literature underscores that proper counseling and dialogue often convince Jehovah's Witnesses to accept a blood transfusion [4]. This position would enable health team to gather relevant information about the child, his immediate family structure, the number of family member, family's financial condition, emotional stability, cultural belief, and parental attitude towards child's wellbeing etc. This position not only prevents the coercion and paternalistic approach of healthcare team members towards child's parents but also enables family members to take a decision in the best interest of child after considering possible physical, financial, emotional, and social consequences. Literature highlights that decisions undertaken by the surrogates having a biological or social relationship with patients are reflective of the patients' values [8].
B. Consequences: Assisting parents to decide in the best interest of the child would demand time, energy, and constant efforts by health team. Time spent on counseling might cause a delay in child's treatment. The health team may face time constraints as they have to manage patient's condition while looking after other routine tasks. So, there are possibilities that other patients may get neglected at health care setting. Though this position is safe and effective, several uncertainties are attached to this position because after counseling child's parents might accept or reject the safest treatment option i.e., transfusing somebody else's blood. In the case of parents' denial for the safest option, disharmony could result in the health care setting. The situation could become stressful for child's family, health team, and all other if child's death occurs.

\section{Recommendations}

The major recommendation from the discussed clinical scenarios is that it is imperative that the healthcare professionals must critically analyze the ethical dilemma, identify positions as per the nature of the scenario, and examine the short term and long-term consequences of the identified positions before taking the final decisions. In case of surrogate decision making in the pediatric settings, healthcare professionals must involve family members in all steps of the minor's treatment plan and healthcare decision making. Besides that, counseling facilities should be made available for patient's family and health team members to facilitate their coping with these stressful situations. At level, availability of policies on there fusal of blood transfusion will assure uniformity in healthcare practices and provision of culturally-sensitive care. In medical and nursing schools, ethics and sociology should be taught as the compulsory courses to better prepare them to enable them to take ethically, morally and culturally appropriate decisions in practice setting.

\section{References}

1. Linnard Palmer L, Kools S (2004) Parents' refusal of medical treatment based on religious and/ or cultural beliefs: The law, ethical principles, and clinical implications. Journal of Pediatric Nursing 19 (5): 351-355.

2. Burkhardt M, Nathaniel A (2002) Ethics \& Issues in Contemporary Nursing ( $2^{\text {nd }}$ edn.) Delmar, Australia.

3. Diekema DS (2004) Parental refusals of medical treatment: The harm principle as threshold for state interventions. Theoretical Medicine 25: 243-264.

4. Macklin R (2003) Applying the four principles. Journal of Medical Ethics 29: $275-280$.

5. Beauchamp T, Childress J (2001) Principles of Biomedical Ethics (5 $5^{\text {th }}$ edn.) Oxford University Press, New York, USA.

6. Aroskar MA (1980) Anatomy of an ethical dilemma: the theory. American Journal of Nursing 80: 658-663.

7. Cushing M (1982) whose best interest? Parents vs. child rights. American Journal of Nursing 82 (2): 313-314.

8. Rhodes R, Holzman I (2004) The not unreasonable standard for assessment of surrogates and surrogate decisions. Theoretical Medicine 25: 367-385. 
9. Butler C (2009) Transfusion issues in Thalassemia.

10. World Health Organization (2008) Universal Access to Safe Blood transfusion.

11. Watt J (1994) Alternative management procedures should be used. British Medical Journal 308: 1424 .

12. Franca IS, Baptista RS, Brito VR (2008) Ethical dilemma in blood transfusion in Jehovah's witnesses: A legal-bioethical analysis. Acta Paulista de Enfermagem 21(3): 498-503.

13. Hickey K, Lyckholm L (2004) Child welfare versus parental autonomy: Medical ethics, the law, and faith-based healing. Theoretical Medicine 25: $265-276$.
14. Chua R, Tham KF (2006) Will “no blood” kill Jehovah Witnesses? Singapore Medical Journal 47 (11): 994-1001.

15. Woolley S (2005) Children of Jehovah's Witnesses and adolescent Jehovah's Witnesses: What are their rights? Archives of diseases in Childhood 90(7): 715-719.

16. Sheldon M (2004) Medical decision-making for children and the question of legitimate authority. Theoretical Medicine 25: 225-228.

17. Gillon R (2000) Refusal of potentially life-saving blood transfusion by Jehovah's Witnesses: should doctors explain that not all JWs think it's religiously required? Journal of Medical Ethics 26: 299-301.

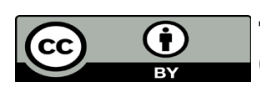

This work is licensed under Creative Commons Attribution 4.0 License

Submission Link:

$$
\text { Submit Article }
$$

DOI: $10.32474 /$ PAPN.2018.01.000104

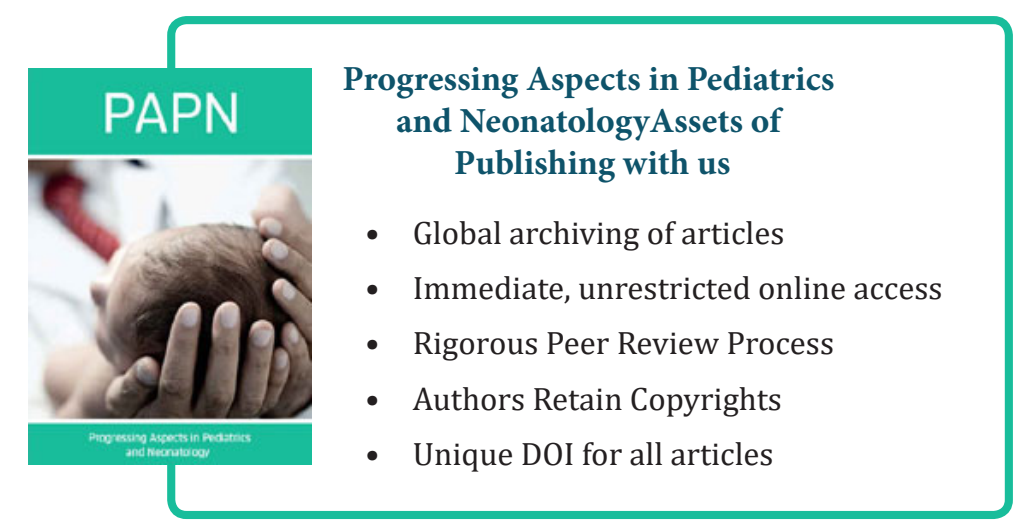

